\title{
Anxiety and depressive symptoms related to parenthood in a large Norwegian community sample: the HUNT2 study
}

\author{
Tormod Rimehaug · Jan Wallander
}

Received: 6 October 2008/Accepted: 24 July 2009/Published online: 11 August 2009

(c) The Author(s) 2009. This article is published with open access at Springerlink.com

\begin{abstract}
Introduction The study compared anxiety and depression prevalence between parents and non-parents in a society with family- and parenthood-friendly social politics, controlling for family status and family history, age, gender, education and social class.

Methods All participants aged 30-49 $(N=24,040)$ in the large, non-sampled Norwegian HUNT2 community health study completed the Hospital Anxiety and Depression Scales.

Results The slightly elevated anxiety and depression among non-parents compared to parents in the complete sample was not confirmed as statistically significant within any subgroups. Married parents and (previously unmarried) cohabiting parents did not differ in portraying low anxiety and depression prevalence. Anxiety was associated with single parenthood, living alone or being divorced, while elevated depression was found only among those living alone.

Discussion Burdening selection and cultural/political context are suggested as interpretative perspectives on the contextual and personal influences on the complex relationship between parenthood and mental health.
\end{abstract}

Keywords Single parents - HADS - Cohabitation · Divorce $\cdot$ Selection

T. Rimehaug ( $\square)$

Regional Centre for Child and Adolescent Mental Health,

Norwegian University of Science and Technology (NTNU),

7489 Trondheim, Norway

e-mail: Tormod.Rimehaug@ntnu.no

J. Wallander

University of California, Merced, CA, USA

\section{Introduction}

Despite the central importance of parenthood as a social role, studies of its possible associations with mental health have produced inconsistent results. An early review from 1987 [29] suggested increasingly negative impact on psychological well-being from parenthood, while a review in 1990 [35] reported positive as well as negative effects of parenthood, both reviews reporting considerable differences across studies and between subgroups of parents. These earlier reviews as well as more recent research suggest that the associations between parenthood and mental health are complex, depending on the interplay of multiple individual, familial and contextual factors, and are also influenced by society and culture, possibly affecting subgroups differentially. However, the research on parenting is dominated by North American studies restricting the variation in factors influenced by society. The only large-scale study we have found analysing multiple factors and parent groups is from the US [12]. Therefore, the present study from Norway represents an important expansion of the knowledge base.

The large-scale $(N>13,000)$ study from the US by Evenson and Simon [12] explored multiple parent and family constellations, contrasted parents with non-parents, and included both sexes. This publication found not only larger variation, but also an average elevated level of depression among all parent groups-especially non-custodial parents. However, the study did not address other aspects of mental health than depression and had active oversampling of multiple disadvantaged groups. Other studies from the US National Survey of Families and Households (NSFH) have shown parental depression to vary with contextual factors such as ethnicity [21], single parenthood [9] and divorce among men [22], and when 
focusing specifically on the passage into parenthood, change in depression depends on gender and relationship history [34].

Most prior studies have addressed general well-being or distress, reported on only depression as a mental health indicator, or did not report actual symptom levels or prevalence of clinically relevant elevations. These deficiencies have made it difficult to evaluate the public health importance. Contributing to the lack of clarity is that many previous studies have been small, limited in scope, or date back several decades. Moreover, methodological limitations include lacking vital comparison groups of non-parents [13], single or cohabiting persons [9], or even fathers [41], or ignoring prior marital history as a factor [4]. Also defining parenthood mainly as a biological state in contrast to a social role, or focus specifically on the passage into parenthood can confuse important subgroups of parents (e.g. empty-nested, non-custodial/non-resident, new/experienced parents and step parents). Similarly, single parents are rarely differentiated into those who are truly a single parent versus those who are cohabiting. Even a relatively large $(N>5,000)$ Canadian study showing more psychological distress and alcohol consumption among single parents compared to couples controlled only for gender and age [3], lacking cohabitation and marital history as differentiation factors. The present study was designed to address several of these deficiencies, while concentrating on parenthood as a social role.

Research restricted geographically to North America has been less able to illuminate the possible impact of differences of the socio-political context and cultural norms relevant to parenthood. A recent report on public investments in children and families ranks Norway in the top group of 21 OECD countries (e.g. for $\%$ of gross domestic product, $\%$ of public spending, US\$ spent per child in the population, \% increase in these investments from 1980 to 2000). In contrast, US was ranked towards the bottom on all indicators, and has showed a worsening historical trend [15]. In Norway, 54\% of all babies have unmarried parents, but this breaks out to $42 \%$ cohabiting parents and only $11 \%$ single mothers [38]. In the US, $37 \%$ of all births are to unmarried parents [32], but official statistics do not differentiate cohabiting from single mothers. The overall parental cohabitation rate is $8.2 \%$ in the US [2] in contrast to $24.5 \%$ in Norway. In both countries, single parenthood is still associated with poorer health, less education, and lower income, but this is more pronounced in the US. These differences may influence parental mental health, enabling the present study from Norway to shed some light on the influence of contextual and cultural factors on the associations between parenthood and mental health.

Based on prior studies, we suggest that the mental health consequences of parenthood are largely dependent on interactions with contextual factors, which can easily be confused with personal history and selection effects. Our aim with this study is to utilize data from a large community health survey to examine multiple subgroups of parents and non-parents of both sexes. Because prevalence differences in anxiety and depression have been documented in connection with gender [16], age [30], education, and marital status [40], it was important to control for the separate influences from and possible interactions with these status characteristics. Our hypothesis is that parenthood is indirectly associated with mental health depending on contextual factors and personal history, and will appear somewhat more positively when investigating a population where cultural and socio-political factors are more familyand parenthood friendly than in the US.

\section{Methods}

\section{Subjects}

The Nord-Trøndelag Health Study (HUNT2) is a nonsampled data collection from a substantial majority of the total adult population 20-100 years old in all municipalities in the Nord-Trøndelag county of Norway [19]. The area has a highly stable population including coastal, inland rural areas and several small towns. The ethnicity of this population is highly homogeneous, including only a very small element of non-western immigrant $(<1 \%)$ [11] as well as indigenous people $(<1 \%)$ [37]. Of the 92,100 invited by mail, 65,648 (71\% of the population) participated and 59,930 (65\%) completed a health survey including the mental health questionnaire used in this study [19]. Thus, there is no bias from a sampling procedure, but there was a non-random drop-out rate of $29 \%$. Among nonresponders, $13 \%$ were unwilling to participate in the study, $21 \%$ forgot to complete the instrument, and $66 \%$ were practically impeded from doing so [20].

The present study restricted the age-span 30-49 years to reduce ambiguity of parenthood. Including the age-span 20-30 would have added few parents and included many future parents as non-parents. Including adults older than 50 years would have polluted the non-parents group with many "empty-nested" former parents due to our parenthood definition (see below). The exact age cutpoints were kept at 30-49 years of age to enable comparison with other publications from HUNT2 and with public statistics. Exclusion of those with partially missing data and ambiguous parenthood information reduced the response rate from 72 to $70 \%$. The final sample of $N=24,040$ aged 30-49 included $75 \%$ of all "active" parents in HUNT2: $65 \%$ of the women and $56 \%$ of the men were parents. 


\section{Measures}

Here, the concepts of anxiety and depression are used to denote the presence of clinical symptoms above a defined cutpoint, not as the presence of an anxiety or depressive disorder. The Hospital Anxiety and Depression Scale (HADS) [36] contains two symptom scales with seven items rated on four-point scales each for anxiety and depression. The two scales show good internal consistency and a stable two-factor structure in numerous studies [6, 28] as well as in the HUNT2 study (consistency $\alpha=0.78$ for anxiety and $\alpha=0.80$ for depression). The two HADS scales have reasonable sensitivity and specificity, which has averaged 0.80 across multiple studies in identifying unspecified anxiety or depressive disorders [6], using a score of 8 or above as cutpoint for each scale, also used in validation studies and in surveys in clinical populations $[18,36]$. The anxiety scale mainly focuses on the restlessness-tension and worry-panic dimensions of anxiety (e.g. A/1 "I feel tense and wound up"). The depression scale mainly focuses on anhedonia, a main feature of depressive states (e.g. D/10 "I have lost interest in my appearance") [18]. The validity of HADS has been satisfactory in numerous analyses [6, 18, 31]. Across ages 1865, population prevalence estimates in HUNT2 are 9.2\% for depression and $15.6 \%$ for anxiety, compared to 5.3 versus $11.1 \%$ depressive disorders and 10.5 versus $15.5 \%$ anxiety disorders in other rural versus urban Norwegian areas [24].

Parenthood was defined by social criteria, inferred from marital status, age, and household composition information because direct parenthood information was not available in the HUNT2 database. Erring on the side of over-exclusion when information on relationship status was ambiguous resulted in 362 adults residing with children being excluded when other information suggested they were not likely a parent. A combined family status variable was constructed, incorporating information on current partnership (single, married, cohabiting), marital history (divorced, widowed, unmarried) and parenthood (parent or not) into 14 known categories (marital history could not be differentiated for those married). The categories are listed in the first column of Table 2. Education level was expressed in years, and social class coded on the basis of occupation [25].

\section{Statistics}

For continuous variables, Pearson product moment coefficients were used to examine relationships between variables, and differences between group means were analysed using ANOVA. Differences in anxiety or depression prevalence were analysed with $\chi^{2}$ or with odds ratios (OR) in logistic regression. Due to multicolinearity, the ordinary logistic regression approach (entering parenthood, current partnership, and divorce as separate factors into regression models) resulted in unstable models and possible Type II errors, especially if allowing for interaction effects. To avoid this problem, the combined family status variable was used for multiple simple comparisons between subgroups in logistic regressions, using "married parent" as a common reference group or by selecting a pair of subgroups only for a specific comparison. In all logistic regressions, age, gender, education level and social class were included in models as control variables; however, excluding them did not alter the statistical significance of any of the reported differences.

Because of the large number of subjects $(N=24,040)$ and accordingly high statistical power, a minimum level of $p<0.005$ was used to indicate statistical significance in analyses. The relative importance of significant results was evaluated using prevalence rates and effect size by means of OR for logistic regression analyses. All results based on dichotomous HADS variables as dependent variables (DVs) were compared with those from equivalent analyses on continuous HADS scores as DVs. Because these results were highly similar, only the analyses on dichotomous variables are reported herein.

The Nord-Trøndelag Health Study was approved by the National Data Inspectorate and the Board of Research Ethics in Health Region IV of Norway.

\section{Results}

Descriptive statistics on anxiety and depression overall and for subgroups are presented in Table 1. There was a strong positive correlation between anxiety and depression symptom scores for the total sample, $r=0.61, p<0.001$. Likewise, there was an association between clinical levels of anxiety and depressive symptoms, $\chi^{2}(1)=3967$, $p<0.001$, such that 16.2 and $8.4 \%$ of all participants reported clinical levels of anxiety and depression symptoms, respectively, and $5.5 \%$ reported both. Social class and education level initially appeared to be associated with the probability of being married versus cohabiting, but when controlling for age, these associations disappeared.

Marital history, which was only available for those presently not married $(N=8,332)$, was unevenly distributed. Only $2 \%(n=182)$ were widowed. Among those presently not married, $26 \%$ of cohabiting persons were divorced compared to the significantly higher $33 \%$ among single persons $\left(\chi^{2}(1)=42.53, p<0.001\right)$. Of single parents, $57 \%$ were divorced versus $26 \%$ of single non-parents (contrast $\left.\chi^{2}(1)=297.6, p<0.001\right)$. Finally, 23\% of cohabiting parents were divorced versus $38 \%$ of cohabiting non-parents (contrast $\chi^{2}(1)=82.10, p<0.001$ ). These 
Table 1 Descriptive statistics for anxiety and depression for parents and non-parents by partnership and gender

\begin{tabular}{|c|c|c|c|c|c|}
\hline & \multirow[t]{2}{*}{$N$} & \multicolumn{2}{|l|}{ Anxiety } & \multicolumn{2}{|l|}{ Depressiveness } \\
\hline & & $\begin{array}{l}\text { Cut-off } \\
\text { prevalence }(\%)\end{array}$ & $\begin{array}{l}\text { Scale, } \\
M \text { (SD) }\end{array}$ & $\begin{array}{l}\text { Cut-off } \\
\text { prevalence }(\%)\end{array}$ & $\begin{array}{l}\text { Scale, } \\
M(\mathrm{SD})\end{array}$ \\
\hline \multicolumn{6}{|l|}{ Women } \\
\hline \multicolumn{6}{|l|}{ Married } \\
\hline Non-parents & 2,777 & 18.0 & $4.6(3.4)$ & 7.8 & $3.1(2.8)$ \\
\hline Parents & 5,883 & 15.8 & $4.4(3.3)$ & 7.3 & $2.8(2.8)$ \\
\hline \multicolumn{6}{|l|}{ Cohabiting } \\
\hline Non-parents & 417 & 24.5 & $5.0(3.6)$ & 7.7 & $3.1(2.8)$ \\
\hline Parents & 1,587 & 18.0 & $4.5(3.4)$ & 8.3 & $3.0(2.9)$ \\
\hline \multicolumn{6}{|l|}{ Single } \\
\hline Non-parents & 1,197 & 23.7 & $5.0(3.9)$ & 10.6 & $3.3(3.2)$ \\
\hline Parents & 724 & 27.6 & $5.5(4.0)$ & 12.4 & $3.4(3.3)$ \\
\hline \multicolumn{6}{|l|}{ Men } \\
\hline \multicolumn{6}{|l|}{ Married } \\
\hline Non-parents & 2,343 & 12.8 & $4.0(3.1)$ & 8.1 & $3.3(2.9)$ \\
\hline Parents & 4,705 & 12.3 & $4.0(3.0)$ & 7.8 & $3.2(2.8)$ \\
\hline \multicolumn{6}{|l|}{ Cohabiting } \\
\hline Non-parents & 517 & 15.7 & $4.2(3.3)$ & 7.7 & $3.1(2.8)$ \\
\hline Parents & 1,493 & 13.7 & $4.2(3.0)$ & 6.8 & $3.1(2.7)$ \\
\hline \multicolumn{6}{|l|}{ Single } \\
\hline Non-parents & 2,202 & 17.8 & $4.6(3.6)$ & 12.4 & $3.7(3.3)$ \\
\hline Parents & 195 & 23.6 & $5.4(3.6)$ & 14.4 & $3.9(3.4)$ \\
\hline
\end{tabular}

differences identify mild multicolinearity among grouping variables. In addition, the association between having a partner (married or cohabiting) and being a parent $\left(\chi^{2}(1)=3423, p<0.001\right)$ represented a moderate colinearity, but there is no general association between divorce and parenthood.

Simple comparison between parents and non-parents revealed non-parents to have higher prevalence of anxiety (18 vs. $\left.15 \%, \chi^{2}(1)=20.64, p<0.001\right)$ as well as depression ( 9 vs. $8 \%, \chi^{2}(1)=14.43, p<0.001$ ). When controlling for education, social class, age and gender, the difference in anxiety was still significant, but not the difference in depression.

\section{Anxiety regressed on combined family status variables}

To test thoroughly whether parenthood was associated with differences in anxiety, the parents were contrasted to equivalent non-parents within each subgroup defined by partnership status and history. No statistically significant differences between parents and non-parents were found within the seven subgroup comparisons.

Then to clarify what did characterize persons with elevated anxiety, we compared all other family status subgroups to "married parents" as the reference group. The resulting logistic regression statistics are shown in Table 2, and Fig. 1 illustrates anxiety prevalence for most of the combined family status subgroups (the four subgroups involving widowed persons are not shown in Fig. 1 because of small $n<=70$ ).

The results in Table 2 suggested "divorced" or "single and never married" as the common characteristics of groups with elevated anxiety (plus the small group of widowed single parents). To elaborate the influence of divorce, the "divorced" subgroups were contrasted to the equivalent "never married" subgroup (first among cohabiters only, then among single persons only): Those "divorced and cohabiting" had significantly higher anxiety prevalence than those "never married and cohabiting" $[B$ $(\mathrm{SE})=0.33(0.09), \mathrm{OR}=1.38, p=0.001]$, and those "divorced and single" had higher anxiety prevalence than those "never married and single" $[B(\mathrm{SE})=0.43(0.08)$, $\mathrm{OR}=1.54, p<0.001]$. Further elaboration for the influence of being single, single groups were contrasted to their equivalent cohabiting subgroup. These analyses revealed an important nuance in that single status appeared to have influence on anxiety only in combination with parenthood. Single parents showed significantly higher anxiety prevalence than cohabiting parents $[B \quad(\mathrm{SE})=0.55 \quad(0.09)$, $\mathrm{OR}=1.73, p<0.001]$; however, there was no difference between single and cohabiting non-parents, or between single parents and single non-parents. This interaction did not show itself clearly when single persons were first contrasted to married parents. 
Table 2 Regression of anxiety and depression on family status categories

\begin{tabular}{|c|c|c|c|c|c|c|}
\hline \multirow{2}{*}{$\begin{array}{l}\text { Marr Par (reference category } \\
\text { for simple contrasts) }\end{array}$} & \multicolumn{3}{|c|}{ Clinical level of anxiety } & \multicolumn{3}{|c|}{ Clinical level of depression } \\
\hline & $B(\mathrm{SE})$ & OR & $95 \% \mathrm{CI}$ & $B(\mathrm{SE})$ & OR & $95 \% \mathrm{CI}$ \\
\hline Marr NoPar & $0.04(0.05)$ & ns & & $-0.17(0.07)$ & ns & \\
\hline Um Coh NoPar & $0.26(0.12)$ & ns & & $-0.17(0.18)$ & ns & \\
\hline Um Coh Par & $0.06(0.07)$ & ns & & $0.09(0.09)$ & ns & \\
\hline UmSing NoPar & $0.31(0.06)$ & $1.36^{* *}$ & $1.21-1.54$ & $0.42(0.08)$ & $1.52 * *$ & $1.31-1.78$ \\
\hline Um Sing Par & $0.53(0.13)$ & $1.70^{* *}$ & $1.32-2.18$ & $0.73(0.16)$ & $2.07 * *$ & $1.51-2.85$ \\
\hline Wi Coh NoPar & $0.15(0.50)$ & ns & & $-0.31(0.74)$ & ns & \\
\hline Wi Coh Par & $0.28(0.46)$ & ns & & $0.14(0.61)$ & $\mathrm{ns}$ & \\
\hline Wi Sing NoPar & $0.23(0.34)$ & ns & & $-0.06(0.40)$ & ns & \\
\hline Wi Sing Par & $0.87(0.29)$ & $2.39 * *$ & $1.35-4.24$ & $0.29(0.44)$ & ns & \\
\hline Div Coh NoPar & $0.56(0.13)$ & $1.74 * *$ & $1.35-2.25$ & $0.08(0.18)$ & $\mathrm{ns}$ & \\
\hline Div Coh Par & $0.37(0.10)$ & $1.44 * *$ & $1.19-1.75$ & $0.17(0.14)$ & $\mathrm{ns}$ & \\
\hline Div Sing NoPar & $0.75(0.08)$ & $2.12 * *$ & $1.80-2.49$ & $0.54(0.10)$ & $1.72 * *$ & $1.40-2.10$ \\
\hline Div Sing Par & $0.83(0.10)$ & $2.29 * *$ & $1.87-2.80$ & $0.59(0.14)$ & $1.80 * *$ & $1.37-2.37$ \\
\hline Constant & $-1.88(0.18)$ & $0.15^{* *}$ & & $-3.47(0.24)$ & $0.31 * *$ & \\
\hline
\end{tabular}

The control variables such as age, gender, education and social class are not displayed in this table

Marr married, Um unmarried, Wi widowed, Div divorced, Coh cohabiting, Sing single, Par parent, NoPar non-parent

$* * p<0.005$

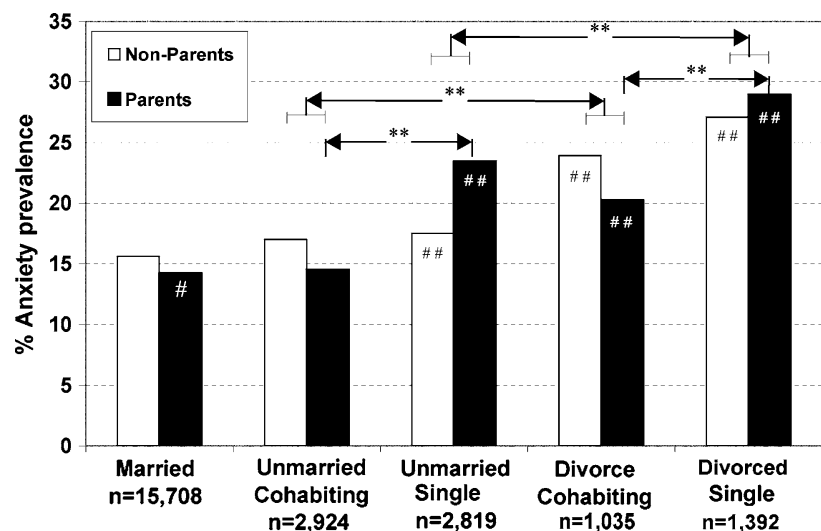

Fig. 1 Anxiety prevalence for selected family status subgroups. \# Reference group, significant OR comparison to reference group (married parents) \#\#p <0.005, significant OR contrasts $* * p<0.005$

The control variables gender [female $=1: B(\mathrm{SE})=$ 0.34 (0.04), $\quad \mathrm{OR}=1.40, \quad p<0.005]$, education level $[B(\mathrm{SE})=-0.11(0.02), \mathrm{OR}=0.90, p<0.005]$ and social class $[B \quad(\mathrm{SE})=-0.02(0.01), \quad \mathrm{OR}=0.98, \quad p<0.05]$ showed significant associations with anxiety, but age did not. Interactions between these control variables and other variables were not significant.

Depression regressed on combined family status variables

To test thoroughly whether parenthood was associated with differences in depression prevalence, parents were

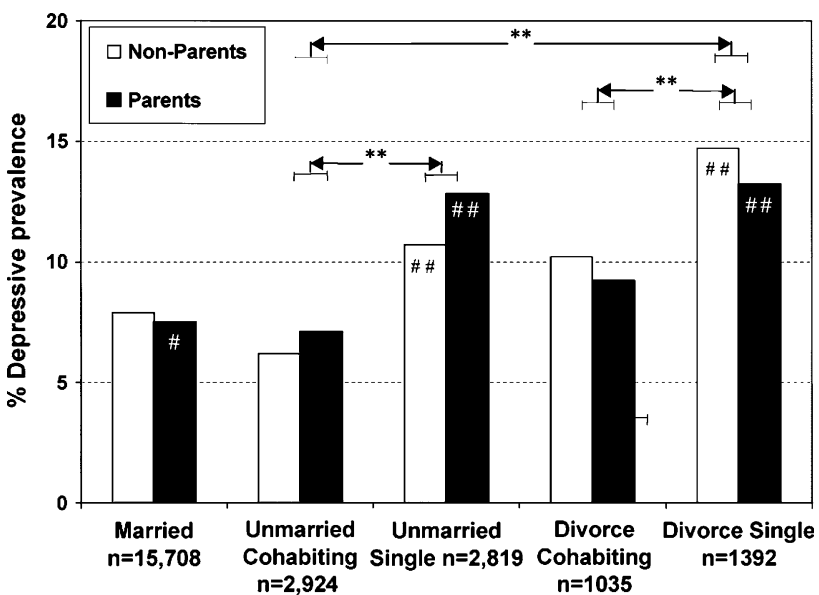

Fig. 2 Depression prevalence for selected family status subgroups. \# Reference group, significant OR comparison to reference group (married parents) \#\#p <0.005, significant OR contrasts $* * p<0.005$

compared to equivalent non-parents within each subgroup defined by partnership status and history. No statistically significant differences between parents and non-parents were found in the seven possible comparisons.

The preliminary impression when inspecting Fig. 2 was that subgroups with elevated depression prevalence were characterized by single persons, possibly with higher prevalence if divorced. However, statistical analyses did not quite confirm this: Contrasting all other family status subgroups with "married parents", as the reference group showed that single status was the only common feature among subgroups with elevated depression (see Table 2). 
Elaborating this with other contrasts confirmed this conclusion: Those "divorced and single" had significantly higher depression than "divorced cohabiters" $[B$ $(\mathrm{SE})=0.42(0.13), \mathrm{OR}=1.52, p=0.001]$, and those "never married single" had higher depression prevalence than "never married cohabiters" $[B(\mathrm{SE})=0.43(0.10)$, $\mathrm{OR}=1.53, p<0.001]$. However, "divorced cohabiters" did not have significantly increased depression prevalence contrasted to any married or unmarried groups. This indicated that the single status was more important than the divorce history in relationship to depression.

The control variables education level $[B(\mathrm{SE})=-0.16$ (0.02), OR $=0.85, p<0.005]$ and age $[B(\mathrm{SE})=0.04$ (0.01), $\mathrm{OR}=1.04, p<0.005]$ had statistically significant associations with depression prevalence, but gender and social class did not. Interactions between these control variables and the other available variables were not significant.

\section{Discussion}

The results of this study support the perspective that the associations between parenthood and mental health are complex and highly dependent on contextual factors. It is theoretically interesting and in contrast to many previous US studies [12,29] that the initial simple analysis indicated a lower prevalence of both anxiety and depressive symptoms among parents compared to non-parents. However, the differences are too small to have any public health significance. Moreover, further analysis showed that these parent/non-parent differences were in part confounding effects of relationship variables, and were also inconsistent across specific subgroups.

The majority groups of married parents and cohabiting parents without a prior divorce share the absolute base level of anxiety and depression prevalence with non-parents in the same subgroups. In contrast, the small subgroup of single parents showed only a moderate elevation in prevalence of anxiety if never married, but doubled anxiety prevalence if a divorce was part of their relationship history. However, these elevations were not significantly different from equivalent non-parents subgroups, suggesting that being a parent does not represent the risk associated with these subgroups. Depressive prevalence showed a somewhat similar picture with almost twice as high as prevalence among all single persons regardless of parenthood, also pointing towards other factors than parenthood in itself. Finally, the effects of social class and education were small in a population perspective, and did not influence the conclusions regarding parenthood or other family status characteristics. We will now address methodological issues, before we discuss interpretations.
Methodological issues

The broad epidemiological perspective of this study may conceal effects on mental health of specific parenting events (e.g. becoming a parent, births of additional children) as well as on the challenges associated with certain stages of parenting (e.g. caring for infants or adolescents). Based on the overall results, however, these events or stages do not seem to result in longer term effects on mental health, or else parents overall would report a reduced mental health. There may be transient effects, or these effects are relevant only to limited groups. Alternatively, such specific negative influences are outweighed by positive parenthood factors across time.

An advantage of the database utilized for the present study is that the recruitment methodology reduced the influence of sampling bias because the entire population of a geographical area was personally invited. The present study included parents with decades of caregiving experience as well as new parents and non-parents, differentiated gender and single as well as married and cohabiting persons, and allowed some differentiation based on prior marital history. At the same time, this database has limitations, in particular by not identifying non-custodial biological parents or adoptive or foster parents, or specifying prior marital history for those currently married. Neither can it identify "empty-nested" parents, which required the exclusion of age groups above 50, where the rate of "empty-nested" parents rises steeply. Because Norway is highly homogeneous, especially in the targeted geographic region, this study was also insensitive to factors associated with ethnicity or migration, which can be powerful contextual factors for parenthood in some populations.

The large statistical power in this study implies that statistical significance could be attained for minor effects when analysing the entire sample. On the other hand, important effects can become rejected as statistically nonsignificance because they are represented by small subgroups. This may be a particular problem for the small group of widowed persons in the present study. Using cutoff categorizations of anxiety and depression could have reduced the statistical sensitivity to differences in smaller subgroups, but analyses of continuous variables did not confirm this.

Coding parenthood based on combining family composition and age implies a danger of misclassifications into both parents and non-parents. The exclusion of persons below 30 and above 50 years of age and 362 individuals with ambiguous information reduced but did not rule out this weakness. If the survey database had included direct questions on parenthood, this limitation would have been removed. 
Interpretations focused on relationship history and consequences

The traditional interpretation when finding a reduced mental health among single parents has been focused on the strains and disadvantages of combining parenthood with having to handle responsibilities and problems alone $[3,9]$. However, single parents are not necessarily negatively burdened by increased workload and responsibility. A recent study on economically poor single mothers showed a positive mental health effect of full-time employment despite small economic gains [45]. In a study of single mothers specifically, mental health problems was limited to divorced single mothers and not observed in the never married single mothers [1], but the study lacked a non-parent comparison. Indeed, divorce and particularly multiple relationship transitions have been associated with increased anxiety and depression in several previous studies, which has usually been interpreted as resulting from emotional, social and practical strains [42]. Thus, relationship history may be part of the explanation why single parenthood is associated with reduced mental health.

In addition to prior and present strains, a selection process may also be part of the explanation. However, several studies fail to find a selection effect of anxiety or depression related to marriage [26, 34, 44]. In contrast, studies have shown that both depression and anxiety predict divorce and marital instability over the lifetime [40, 41], and that depression is retained across divorce and remarriage [41], at least partly [43]. This is consistent with findings that anxiety as well as depression is often stable or recurrent over time [8, 39], thus possibly contributing to difficulties in maintaining relationships. Hence, the observed elevated anxiety and depression may reflect one of the causes of divorce and therefore single status, and not only reflecting prior and present strains. Our study was not designed to disentangle relationship history in detail. It will be important in future studies on the mental health of different groups of parents to collect such information.

\section{Interpretation focused on social-political context}

The result of the present study diverges in part with previous research [7, 9, 17] in not finding an elevated depressive prevalence among single parents (there was only an elevated anxiety prevalence), no mental health difference between married and cohabiting couples (unless divorced), and no differential patterns between mother and father. One interpretative approach to these differences with these previous studies conducted in the US is the social and political difference regarding families and parenthood between the US and Norway. More specifically, there are legal and economic differences as well as differences in attitudes, values, and practices regarding parenthood, single parenthood, divorce, cohabitation, and gender equality between the two countries. Generally, providing advantages for parenting in Norway, these differences may lessen some of the negative effects of parenthood or a disadvantaged situation for some groups in American society. The Norwegian socio-political and cultural context implies that cohabiting parents and single parents as groups are less selected and less stigmatized than in the USA, and live in a society that supports parenthood in legal, economic and practical ways regardless of marital status. From Denmark, where attitudes and social policy are similar, a large twin-study reported substantial positive effect from having a first-born child on well-being and happiness, especially within a relationship, but not when having additional children [23].

In the USA, cohabitation and single parenthood may function as markers for other factors representing the primary mental health risks. For example, US research has led to expectations that cohabiting new mothers are "worse off" than married mothers, because cohabitation is associated with less well-being, poorer health, higher incidence of alcohol abuse and domestic violence, and lower socioeconomic status compared to being married [10], although this has not been a uniform conclusion [44]. However, in Norway, cohabiting persons are almost indistinguishable from those who are married in public statistics on health, psychological, and socio-economic factors [33]. This has been attributed to that cohabitation is a widely accepted, essentially normative living arrangement. Cohabitation is also partly equalized to marriage in selected legal and regulatory reforms, such as regarding insurance coverage and tax benefits [14]. Consequently, cohabitants cannot be expected to be as disadvantaged in Norway as in the US.

Single parents may also be less burdened in Norway than in the US. The Norwegian tax and welfare benefits specifically for single parents, combined with general high minimum wages and low unemployment, constitute a favourable economic context for child-rearing parents, whether in a partnership or single status [5, 34]. Moreover, parenthood is encouraged by generous state benefits for parents and high-quality out-of-home day-care is readily available. Such services may buffer some of the traditional burdens of parenthood, especially for single parents. Active fatherhood is also explicitly valued in public debate and political reforms, such as by including fathers in generous parental leave following birth of a child [27]. These contextual factors can go some way towards equalizing the ongoing burdens of parenthood.

Thus, the results of this study may point to that the contextual factors that societies offer families do make a difference, enabling a more positive parental experience and better mental health for parents of different types. 
Also, differences in family-related norms result in group compositions that change the value of group factors in large-scale studies in different societies. Cross-cultural longitudinal research contrasting such factors and following individual family history are necessary to understand the complex interplay with mental health for the large majority of people who become parents.

Acknowledgments The Nord-Trøndelag Health Study (HUNT) was conducted in collaboration between HUNT Research Centre, Faculty of Medicine, Norwegian University of Science and Technology (NTNU, Verdal), the Norwegian Institute of Public Health, and NordTrøndelag County Council. The HUNT Research Centre supported this study by giving permission to access data.

Open Access This article is distributed under the terms of the Creative Commons Attribution Noncommercial License which permits any noncommercial use, distribution, and reproduction in any medium, provided the original author(s) and source are credited.

\section{References}

1. Afifi TO, Cox BJ, Enns MW (2006) Mental health profiles among married, never-married, and separated/divorced mothers in a nationally representative sample. Soc Psychiatry Psychiatr Epidemiol 41(2):122-129

2. Ambert AM (2005) Cohabitation and marriage: how are they related? The Vanier Institute of the Family, Ottawa. Available from: http://www.vifamily.ca/library/cft/cohabitation.pdf (updated 2005; cited 20 September 2007)

3. Avison WR, Davies L (2005) Family structure, gender, and health in the context of the life course. J Gerontol Ser B Psychol Sci Social Sci 60:113-116

4. Bierman A, Fazio EM, Milkie MA (2006) A multifaceted approach to the mental health advantage of the marriedassessing how explanations vary by outcome measure and unmarried group. J Family Issues 27(4):554-582

5. Bird CE (1997) Gender differences in the social and economic burdens of parenting and psychological distress. J Marriage Family 59(4):809-823

6. Bjelland I, Dahl AA, Haug TT, Neckelmann D (2002) The validity of the Hospital Anxiety and Depression Scale. An updated literature review. J Psychosom Res 52(2):69-77

7. Brown GW, Moran PM (1997) Single mothers, poverty and depression. Psychol Med 27(1):21-33

8. Bruce SE, Yonkers KA, Otto MW, Eisen JL, Weisberg RB, Pagano $M$ et al (2005) Influence of psychiatric comorbidity on recovery and recurrence in generalized anxiety disorder, social phobia, and panic disorder: a 12-year prospective study. Am J Psychiatry 162(6):1179-1187

9. Cunningham AM, Knoester C (2007) Marital status, gender, and parents' psychological well-being. Sociol Inquiry 77(2):264-287

10. DeKlyen M, Brooks-Gunn J, McLanahan S, Knab J (2006) The mental health of married, cohabiting, and non-coresident parents with infants. Am J Public Health 96(10):1836-1841

11. Dzamarija MT, Kalve T (2004) Barn og unge med innvandrerbakgrunn. Statistics Norway, Oslo

12. Evenson RJ, Simon RW (2005) Clarifying the relationship between parenthood and depression. J Health Social Behav 46(4):341-358
13. Flowers AF, Schneider HG, Ludtke HA (1996) Social support and adjustment in mothers with young children. J Divorce Remarriage 25(3-4):69-83

14. Fougner EB (1999) Samboerne og samfunnet. Norwegian Department of Child and Family Affaires, Oslo, p 25

15. Gabel SG, Kamerman SB (2006) Investing in children: public commitment in twenty-one industrialized countries. Social Serv Rev 80(2):239-263

16. Gotlieb IH, Hammen CL (2002) Part I. Descriptive aspects of depression. Handbook of depression. The Guilford Press, NY, pp $1-60$

17. Harrison J, Barrow S, Gask L, Creed F (1999) Social determinants of GHQ score by postal survey. J Public Health Med 21(3):283-288

18. Herrmann C (1997) International experiences with the Hospital Anxiety and Depression Scale-a review of validation data and clinical results. J Psychosom Res 42(1):17-41

19. Holmen J, Midthjell K, Krüger $\varnothing$, Langhammer A, Holmen TL, Bratberg GH et al (2003) The Nord-Trøndelag Health Study 1995-1997 (HUNT 2): objectives, contents, methods and participation. Norsk Epidemiol 13(1):19-32

20. HUNT (2005) Non-responder study. HUNT Research Centre. Available from: http://www.hunt.ntnu.no/index.php?side=forskning/ resultater/deskres/frammote/nonrespond (updated 2005; cited 2 February 2007)

21. Jackson PB (1997) Role occupancy and minority mental health. J Health Soc Behav 38(3):237-255

22. Knoester C, Eggebeen DJ (2006) The effects of the transition to parenthood and subsequent children on men's well-being and social participation. J Family Issues 27(11):1532-1560

23. Kohler HP, Behrman JR, Skytthe A (2005) Partner plus children $=$ happiness? The effects of partnerships and fertility on well-being. Popul Dev Rev 31(3):407-445

24. Kringlen E, Torgersen S, Cramer V (2006) Mental illness in a rural area-a Norwegian psychiatric epidemiological study. Social Psychiatry Psychiatr Epidemiol 41(9):713-719

25. Krokstad S, Westin S (2002) Health inequalities by socioeconomic status among men in the Nord-Trondelag Health Study, Norway. Scand J Public Health 30(2):113-124

26. Lamb KA, Lee GR, DeMaris A (2003) Union formation and depression: selection and relationship effects. J Marriage Family 65(4):953-962

27. Lorensen M, Wilson ME, White MA (2004) Norwegian families: transition to parenthood. Health Care Women Int 25(4):334-348

28. Martin CR (2005) What does the Hospital Anxiety and Depression Scale (HADS) really measure in liason psychiatry settings? Curr Psychiatry Rev 1(1):69-73

29. McLanahan S, Adams J (1987) Parenthood and psychological well-being. Annu Rev Sociol 13:237-257

30. Mirowsky J (1996) Age and the gender gap in depression. J Health Soc Behav 37(4):362-380

31. Mykletun A, Stordal E, Dahl AA (2001) Hospital Anxiety and Depression (HAD) scale: factor structure, item analyses and internal consistency in a large population. $\mathrm{Br} \mathrm{J}$ Psychiatry 179:540-544

32. NCHS (2006) Births: preliminary data for 2005. Hyattsville, MD. Available from: www.cdc.gov/nchs/products/pubs/pubd/hestats/ prelimbirths05/prelimbirths05.htm (updated 2006; cited 10 September 2007)

33. Noack T, Seierstad A (2003) Dagligdags og uttforsket. Samboerskap ved tusenårsskiftet 17(1). Available from: http://www. ssb.no/samfunnsspeilet/utg/200301/05/index.html

34. Nomaguchi KM, Milkie MA (2003) Costs and rewards of children: the effects of becoming a parent on adults' lives. J Marriage Family 65(2):356-374 
35. Ross CE, Mirowsky J, Goldsteen K (1990) The impact of the family on health - the decade in review. J Marriage Family 52(4):1059-1078

36. Snaith RP, Zigmond AS (1994) The hospital and anxiety and depression scale manual. NFER-Nelson, Windsor

37. Statistics_Norway (2006) Samer i Norge. Statistics_Norway, Oslo. Available from: http://www.ssb.no/samer/ (updated 2006; cited 20 September 2007)

38. Statistics_Norway (2007) Høyeste fruktbarhet siden 1991. Available from: http://www.ssb.no/emner/02/02/10/fodte/main. html (September 2007)

39. Tennant $C$ (2002) Life events, stress and depression: a review of recent findings. Aust N Z J Psychiatry 36(2):173-182

40. Turnbull JE, George LK, Landerman R, Swartz MS et al (1990) Social outcomes related to age of onset among psychiatric disorders. J Consult Clin Psychol 58(6):832-839
41. Wade TJ, Cairney J (2000) Major depressive disorder and marital transition among mothers: results from a national panel study. J Nerv Ment Dis 188(11):741-750

42. Willen $H$ (2002) Changing families: public health perspective on divorce. Nordisk Psykol 54(4):271-285

43. Willitts M, Benzeval M, Stansfeld S (2004) Partnership history and mental health over time. J Epidemiol Community Health 58(1):53-58

44. Wu Z, Hart R (2002) The effects of marital and nonmarital union transition on health. J Marriage Family 64(2):420-432

45. Zabkiewicz D (2009) The mental health benefits of work: do they apply to poor single mothers? Social Psychiatry Psychiatr Epidemiol. Available from: http://dx.doi.org/10.1007/s00127-0090044-2 (13 March 2009) 